OPEN ACCESS

Edited by:

Marina De Bernard,

University of Padua, Italy

Reviewed by:

Giampietro Corradin,

University of Lausanne, Switzerland

Syed Faisal Zaidi,

King Saud bin Abdulaziz University for

Health Sciences, Saudi Arabia

*Correspondence:

Sitang Gong

sitangg@126.com

Guoliang Zhang

szdsyy@aliyun.com

Yongjian Wu

wuyongj2@mail2.sysu.edu.cn

Specialty section:

This article was submitted to

Microbial Immunology,

a section of the journal

Frontiers in Immunology

Received: 05 July 2021

Accepted: 18 August 2021

Published: 10 September 2021

Citation:

Ming S, Yin H, Li X, Gong S, Zhang G and Wu Y (2021) GITR Promotes the

Polarization of TFH-Like Cells in Helicobacter pylori-Positive Gastritis.

Front. Immunol. 12:736269.

doi: 10.3389/fimmu.2021.736269

\section{GITR Promotes the Polarization of TFH-Like Cells in Helicobacter pylori- Positive Gastritis}

\author{
Siqi Ming ${ }^{1}$, Huan Yin $^{2}$, Xingyu $L^{2}{ }^{2}$, Sitang Gong ${ }^{3 *}$, Guoliang Zhang ${ }^{1 *}$ and Yongjian $W^{2,3 *}$ \\ ${ }^{1}$ National Clinical Research Center for Infectious Diseases, Shenzhen Third People's Hospital, Southern University of Science \\ and Technology, Shenzhen, China, ${ }^{2}$ Center for Infection and Immunity, the Fifth Affiliated Hospital of Sun Yat-sen University, \\ Zhuhai, China, ${ }^{3}$ Department of Gastroenterology, Guangzhou Institute of Pediatrics, Guangzhou Women and Children's \\ Medical Center, Guangzhou Medical University, Guangzhou, China
}

Gastric $\mathrm{CD} 4^{+} \mathrm{T}$ cells contribute to Helicobacter pylori (H. pylori)-induced gastritis by amplifying mucosal inflammation and exacerbating mucosal injuries. However, the pathogenic $\mathrm{CD}^{+}{ }^{+} \mathrm{T}$ cell subset involved in gastritis and the potential regulators are still unclear. Here we identified an IL-21-producing gastric $C D 4^{+} T$ cell subset, which exhibited tissue-resident $\mathrm{CXCR} 5^{-} \mathrm{BTLA}{ }^{-} \mathrm{PD}-1^{\text {hi }} \mathrm{TFH}$-like phenotype in $\mathrm{H}$. pylori-positive gastritis patients. Meanwhile, we identified glucocorticoid-induced tumor necrosis factor receptor (GITR) as an important regulator to facilitate $\mathrm{IL}-21$ production by $\mathrm{CD} 4^{+} \mathrm{T}$ cells and accelerate mucosal inflammation in gastritis patients with $H$. pylori infection. Moreover, GITR expression was increased in gastric $C D 4^{+} T$ cells of gastritis patients compared to healthy controls, along with the upregulated expression of its ligand GITRL in mucosal macrophages $(M \phi)$ of gastritis patients. Further observations showed that the activation of GITR/GITRL signal promoted the IL-21 production of CD4 ${ }^{+} T$ cells via the STAT3 pathway. Besides this, IL-21 from CD4 ${ }^{+} T$ cells induced the proliferation of $\mathrm{B}$ cell and promoted the production of inflammatory cytokines IL-1 $\beta$ and IL- 6 and chemokines MIP- $3 \alpha$ and CCL25 as well as matrix metalloproteinase (MMP)-3 and MMP-9 by human gastric epithelial cells, suggesting the facilitating effect of IL-21-producing $C D 4^{+} T$ cells on mucosal inflammation and injuries. Taking these data together, we revealed that GITR/GITRL signal promoted the polarization of mucosal IL-21-producing CD4 ${ }^{+} \mathrm{T}$ cells in $\mathrm{H}$. pyloripositive gastritis, which may provide therapeutic strategies for the clinical treatment of H. pylori-induced gastritis.

Keywords: TFH-like cells, $H$. pylori, gastritis, IL-21, GITR

\section{INTRODUCTION}

The interaction between invading pathogens and host immune factors could lead to the formation of an immune microenvironment that fosters chronic inflammation $(1,2)$. Helicobacter pylori $(H$. pylori)-induced gastritis usually results in mucosal injuries and extensive immune cell infiltration (3). Meanwhile, the inflammatory state in the mucosa could, in turn, impact the biological behavior of $\mathrm{H}$. pylori (3). We previously demonstrated that Th9-like MAIT cells are enriched in gastric tissue 
and revealed the positive correlation of Th9-producing MAIT cells with disease progression (4). We also reported that $H$. pylori-associated antigens induced the Th1 and Th17 response of gastric $\mathrm{CD}^{+} \mathrm{T}$ cells (5). These observations indicate the tight interactions between $H$. pylori and the different subsets of immune cells and elements in the mucosal tissue, which may contribute to inflammatory response and mucosal pathology. Therefore, to fully understand the immunopathogenesis of inflammation in H. pylori-positive gastritis, it is critical to elucidate the interaction networks between inflammatory regulators and immune cells within the gastric mucosa.

$\mathrm{T}$ follicular helper (TFH) cell is a special $\mathrm{CD} 4^{+} \mathrm{T}$ cell subset with the ability to induce B cell activation and differentiation (6). In secondary lymphoid tissues, TFH cells take part in the formation of the germinal center (GC) and regulate the development of $\mathrm{T}$ cell-dependent $\mathrm{B}$ cell responses (6). The unique feature of TFH is the high expression of $\mathrm{C}-\mathrm{X}-\mathrm{C}$ motif chemokine receptor 5 (CXCR5), inducible $\mathrm{T}$ cell co-stimulator (ICOS), and programmed cell death protein $1(\mathrm{PD}-1)$ as well as the nuclear transcriptional repressor B cell lymphoma 6 (BCL-6) (7). IL-21, mainly produced by TFH cells, performs a multifunctional role in a broad range of cells. IL-21 receptor (IL-21R) is expressed by a variety of cell types, including myeloid cells, natural killer (NK) cells, B cells, T cells, and non-immune cells (8). IL-21/IL-21R signal could regulate the generation and polarization of $\mathrm{B}$ cells and $\mathrm{T}$ cells and profoundly impact the function of Th cells, plasma cells, plasmablasts, and cells from GC (9-11). Furthermore, IL-21R could also be detected on non-immune cells, including thyroid cells (12), synovial fibroblasts (13), gastrointestinal fibroblasts (14), and gut epithelial cells (15), suggesting the possibly regulatory role of IL-21 for these non-immune cells.

Except for the roles that we introduced above, IL-21 also plays a key role in gastrointestinal mucosal immunity. IL-21expression was higher at the mucosal site of Crohn's disease (CD) patients compared to ulcerative colitis (UC) patients and controls (16). The neutralization of IL-21 reduced the IFN- $\gamma$ production in lamina propria $\mathrm{T}$ cells, which indicates that IL-21 may promote Th1 cell response (16). Furthermore, IL-21 prevents the TGF- $\beta$ dependent polarization of regulatory $\mathrm{T}$ (Treg) cells and promotes the differentiation of Th17 cells in experimental colitis (17). Moreover, IL-21 is highly produced in the gastric mucosa of H. pylori-infected patients (18) and could maintain the proinflammatory $\mathrm{T}$ cell immune response to drive chronic gastritis during $H$. pylori infection (19). However, the regulatory mechanism of IL-21-producing $\mathrm{T}$ cells in $H$. pylori-infected gastritis remains unclear.

The function of TFH cells is regulated simultaneously by the T cell antigen receptor binding strength (20) and the signaling transmission of co-stimulatory receptors (21), for example, CD28 exerts the important function in the early stage of TFH generation, while ICOS is critical in the later phases for TFH cell differentiation (21). In addition, the differentiation of TFH cell is dictated by the balance of cytokines, for example, IL-7 represses TFH cell formation by inhibiting BCL6 and CXCR5 expression (22). IL-12 produced by dendritic cells (DCs) induces the differentiation of IL-21-producing TFH-like cells (23).
Glucocorticoid-induced tumor necrosis factor receptor (GITR) is a member of tumor necrosis factor receptor superfamily (TNFRSF), which is constitutively expressed on $\mathrm{T}_{\text {reg }}$ cells with high levels and at low levels on unstimulated macrophages, T cells, and B cells (24). The trigger of GITR signal could promote effector $\mathrm{T}$ cell activation and reverse the suppressive function of $\mathrm{T}_{\text {reg }}$ cells (25). GITR also influences the progress of gastrointestinal disease by regulating mucosal immunity (26-29). Santucci et al. reported that GITR promotes the development of experimental colitis through enhancing the activation of macrophages and effector $\mathrm{T}$ cells (26). Liao et al. reported that GITR does not directly regulate $\mathrm{T}_{\text {reg }}$ and $\mathrm{T}$ effector cells but appears to promote the development of DCs and monocytes to enhance Th1 cell response, thus aggravating chronic enterocolitis (27). However, Uraushihara reported that GITR-expressing $\mathrm{CD} 4^{+} \mathrm{T}$ cells negatively regulate the intestinal inflammation and mucosal immune responses in experimental colitis (28). Besides this, Sakurai et al. reported that GITR negatively regulates intestinal inflammation by suppressing the IL-15-dependent NK cell activity (29). These studies indicate that GITR exhibits a controversial role in intestinal inflammation.

The role of GITR in $H$. pylori-infected gastritis remains unclear. Here we revealed the role of IL-21-producing TFHlike cells in $H$. pylori-positive gastritis. We identified a class of TFH-like $\mathrm{CD}^{+}{ }^{+} \mathrm{T}$ cells with the capacity to secrete IL-21 in the gastric mucosa of $H$. pylori-positive gastritis patients and demonstrated that the GITR/GITRL axis promoted IL$21^{+} \mathrm{CD} 4^{+} \mathrm{T}$ cell polarization via the STAT3 signal pathway. Moreover, gastric $\mathrm{CD}^{+} \mathrm{T}$ cell-producing IL-21 induced the proliferation of gastric $\mathrm{B}$ cells and the pro-inflammatory cytokines and chemokines as well as the secretion of MMPs by gastric epithelial cells. Collectively, our findings expand the understanding of IL- $21^{+} \mathrm{TFH}$-like $\mathrm{CD}^{+} \mathrm{T}$ cells in $H$. pyloripositive gastritis and investigate the underlying regulatory mechanism, which may provide potential interventions in the clinical treatment of $H$. pylori-induced gastritis.

\section{RESULTS}

\section{Increased IL-21-Producing TFH-Like CD4 ${ }^{+}$ T Cells Are Observed in $\mathbf{H}$. pylori-Positive Gastritis}

To explore the expression pattern of IL-21 in $H$. pylori-positive gastritis, we firstly collected biopsy samples from $H$. pyloripositive gastritis patients and healthy controls (the information of the participants is shown in Table 1) and detected the IL-21 level. The results showed that the co-localization of IL-21 with $\mathrm{CD}^{+} \mathrm{T}$ cells in the gastric mucosa was increased in H. pyloripositive gastritis patients (Figure 1A). In addition, an increased percentage of IL- $21^{+} \mathrm{CD} 4^{+} \mathrm{T}$ cells was detected in biopsy samples from $H$. pylori-positive gastritis patients (Figure 1B). To identify the phenotype of IL- $21^{+} \mathrm{CD} 4^{+} \mathrm{T}$ cells, we analyzed the expression of TFH surface markers BTLA, CXCR5, and PD-1 as well as transcription factor BCL6. Interestingly, the gastric IL $21^{+} \mathrm{CD} 4^{+}$ 
TABLE 1 | Characteristics of healthy controls and gastritis patients.

\begin{tabular}{|c|c|c|c|}
\hline & Healthy & Gastritis & $P$-value \\
\hline Sample size (number) & 20 & 39 & - \\
\hline Age, years (mean $\pm S D$ ) & $\begin{array}{c}29.44 \pm \\
12.65\end{array}$ & $\begin{array}{c}31.35 \pm \\
15.64\end{array}$ & 0.457 \\
\hline $\begin{array}{l}\text { Sex (M/F) } \\
\quad \text { Indication for endoscopy (\%) }\end{array}$ & $11 / 9$ & $17 / 22$ & 0.426 \\
\hline Recurrent abdominal pain & NA & $25(43.8)$ & $<0.001^{\star \star \star}$ \\
\hline Burning abdominal discomfort & NA & $21(53.8)$ & $<0.001^{\star \star \star}$ \\
\hline Acid reflux symptoms & NA & $19(48.7)$ & $<0.001^{\star \star \star}$ \\
\hline Dyspepsia & NA & $22(56.4)$ & $<0.001^{\star \star \star}$ \\
\hline Epigastric pain & NA & $29(74.4)$ & $<0.001^{\star \star \star}$ \\
\hline \multicolumn{4}{|l|}{ Endoscopic finding (\%) } \\
\hline Normal & $20(100)$ & $0(100)$ & $<0.001^{\star \star \star}$ \\
\hline Gastritis & $0(0)$ & $39(100)$ & $<0.001^{\star \star \star}$ \\
\hline $\begin{array}{l}{ }^{13} \mathrm{C} \text {-urea breath test positive }(\mathrm{DOB}>5) \\
(\%)\end{array}$ & $0(0)$ & $39(100)$ & $<0.001^{\star \star *}$ \\
\hline H. pylori infection (\%) & $0(0)$ & $39(100)$ & $<0.001^{\star \star \star}$ \\
\hline
\end{tabular}

The level of significance is evaluated by unpaired Student's t-test or chi-square test.

$P$-value $<0.05$ is considered significant.

F, female; $M$, male; $D O B$, delta over baseline; $N A$, no application.

${ }^{* * *} P<0.0001$

$\mathrm{T}$ cells displayed a distinctive $\mathrm{CXCR}^{-} \mathrm{BTLA}^{-} \mathrm{PD}-\mathrm{1}^{\mathrm{hi}}$ tissueresident activated phenotype compared to $\mathrm{IL} 21^{-} \mathrm{CD} 4^{+} \mathrm{T}$ cells (Figure 1C), whereas classical TFH cells were characterized as $\mathrm{CXCR}^{+}{ }^{+} \mathrm{PD}-1^{+} \mathrm{BTLA}^{+}(7)$. Meanwhile, these IL- $21^{+} \mathrm{CD} 4^{+} \mathrm{T}$ cells expressed a higher level of TFH-specific transcription factor BCL6 than IL21 $1^{-} \mathrm{CD} 4^{+} \mathrm{T}$ cells (Figure 1C). Taking these data together, we found that IL- $21^{+} \mathrm{CD} 4^{+} \mathrm{T}$ cells were increased and exhibited TFH-like phenotype in $H$. pylori-positive gastritis patients compared to healthy controls.

\section{GITR Promotes IL-21 Production of Mucosal TFH-Like Cell Polarization in H. pylori-Positive Gastritis}

GITR has been reported to be related to the differentiation of TFH cells (30). To explore whether GITR facilitated IL-21 production by TFH-like cells in $H$. pylori-positive gastritis, we determined the alternation of IL-21 production after GITR intervention. We firstly analyzed the GITR expression in $H$. pylori-positive gastritis. Consistent with the increased percentage of IL-21-producing TFH-like cells, the expression of GITR was also elevated in mucosal $\mathrm{CD}^{+} \mathrm{T}$ cells from $H$. pylori-positive gastritis patients (Figure 2A). A further analysis indicated that IL- $21^{+} \mathrm{CD} 4^{+} \mathrm{T}$ cells exhibited a higher GITR expression compared to IL-21 ${ }^{-} \mathrm{CD} 4^{+} \mathrm{T}$ cells (Figure $2 \mathrm{~B}$ ). To determine the effect of the GITR/GITRL axis on IL-21 production of FTH-like $\mathrm{CD} 4^{+} \mathrm{T}$ cells, mucosal $\mathrm{CD} 4^{+} \mathrm{T}$ cells were sorted from $H$. pyloripositive gastritis patients and treated with recombinant GITRL protein to activate the GITR on $\mathrm{CD} 4^{+} \mathrm{T}$ cells. After the treatment of mucosal $\mathrm{CD}^{+} \mathrm{T}$ cells with recombinant GITRL, an increased percentage of $\mathrm{IL}-21^{+} \mathrm{CD} 4^{+} \mathrm{T}$ cells was detected (Figures $2 \mathrm{C}, \mathrm{D}$ ). Moreover, the combination of CD3-activating antibody (Ab) with recombinant GITRL further enhanced the IL-21 production of $\mathrm{CD}^{+} \mathrm{T}$ cells (Figures 2C, D). Based on the abovementioned results, we demonstrated that GITR promoted the IL-21 production of mucosal $\mathrm{CD} 4^{+} \mathrm{T}$ cells in $H$. pylori-positive gastritis.

\section{GITRL Is Upregulated in Mucosal Macrophage and Provides a Ligand Signal to TFH-Like Cells}

Next, to investigate the effect of the GITRL/GITR axis on the function of TFH-like cells, we determined the expression and the modulatory role of GITRL in $H$. pylori-positive gastritis patients. GITR is primarily expressed by T cells, and its ligand GITRL is predominantly expressed on myeloid-derived cells, in particular on macrophage $(M \phi)$. We then detected the expression of GITRL on mucosal $\mathrm{M} \phi \phi\left(\mathrm{CD} 11 \mathrm{~b}^{+} \mathrm{HLA}-\mathrm{DR}^{+} \mathrm{CD} 68^{+}\right)$. Consistently, the results showed that GITRL expression was upregulated in the mucosal Mффof H. pylori-positive gastritis patients (Figure 3A). We also found that GITRL expression was raised in monocytederived macrophages (MDM) infected with $H$. pylori (Figure 3B). To further investigate the role of GITRL expressed on M $\phi$ in the IL-21 production of gastric TFH-like cells, we conducted a co-culture assay with MDM and mucosal $\mathrm{CD}^{+} \mathrm{T}$ cells to assess the influence of the GITRL/GITR signal on TFH-like cell activation. MDM was pre-incubated with $H$. pylori to upregulate GITRL expression and then co-cultured with gastric $\mathrm{CD}^{+} \mathrm{T}$ cells in the presence of GITR-blocking $\mathrm{Ab}$, followed by the measurement of IL-21 production. As expected, $H$. pylori primed the MDM-induced IL-21 production by $\mathrm{CD} 4^{+} \mathrm{T}$ cells, while GITR blockage inhibited the IL-21 production induced by $H$. pylori-primed MDM (Figure 3C). These data indicated the crucial role of the GITRL/GITRL signal in TFH-like cell polarization and IL-21 secretion in $H$. pylori-positive gastritis.

\section{GITR/GITRL Axis Promotes the Polarization of IL21 ${ }^{+}$TFH-Like Cells Dependent on the STAT3 Signal Pathway}

We next explored the effect of GITR on the critical signal pathway which mediates TFH-like cell polarization. The STAT3 signal pathway is essential for classical TFH cell polarization (31). We isolated the gastric $\mathrm{CD} 4\langle\sigma \pi\rangle+\langle/ \sigma \pi\rangle \mathrm{T}$ cells and stimulated the cells with recombinant GITRL protein and CD3-activating Ab. The results showed that the phosphorylation of STAT3 of gastric $\mathrm{CD} 4^{+} \mathrm{T}$ cells was increased after stimulation with $\mathrm{CD} 3$-activating $\mathrm{Ab}$ and recombinant GITRL protein. Meanwhile, recombinant GITRL protein synergized with $\mathrm{CD} 3$-activating $\mathrm{Ab}$ further increased the phosphorylation of STAT3 in gastric $\mathrm{CD}^{+} \mathrm{T}$ cells compared to the use of CD3-activating Ab alone (Figure 4A). Furthermore, to investigate whether GITRL in M $\phi$;;could induce STAT3 activation in gastric TFH-like cells, we established the coculture system and found that $H$. pylori-primed $\mathrm{M} \phi$ induced STAT3 phosphorylation in gastric $\mathrm{CD} 4^{+} \mathrm{T}$ cells, while GITR blockage reduced STAT3 phosphorylation induced by H. pyloriprimed M $\phi$ (Figure 4B). We found that classical TFH cell-specific transcription factor BCL6 was increased in gastric IL-21producing TFH-like cells (Figure 1C). To investigate the role of GITR-mediated STAT3 activation in BCL6 expression and IL-21 production, isolated gastric $\mathrm{CD}_{4}^{+} \mathrm{T}$ cells were pretreated with stattic or dimethyl sulfoxide and stimulated with CD3-activating $\mathrm{Ab}$ and recombinant GITRL protein. The activation of the GITR signal enhanced the BCL6 expression and IL-21 secretion in 
A
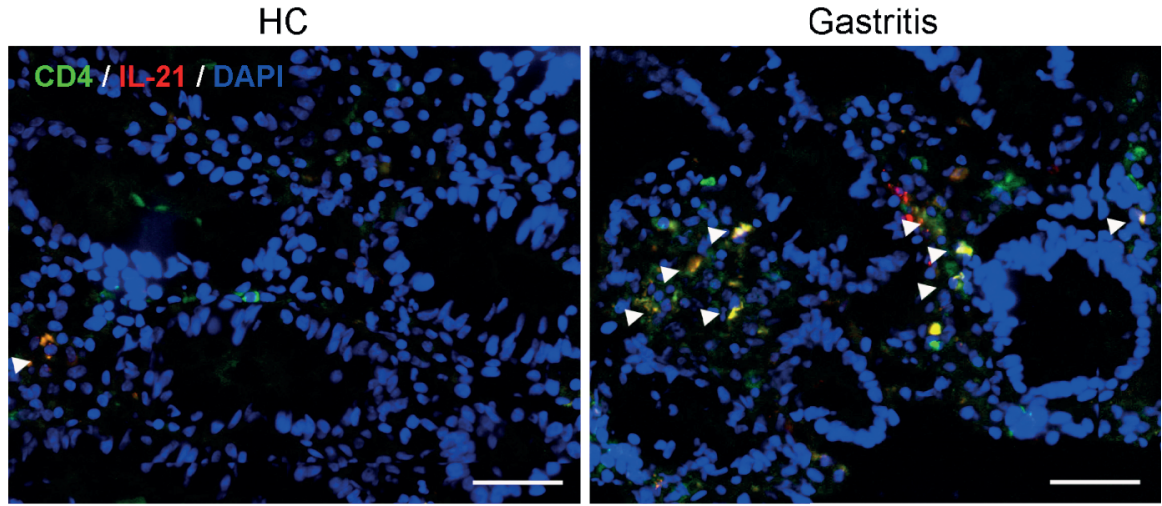

B

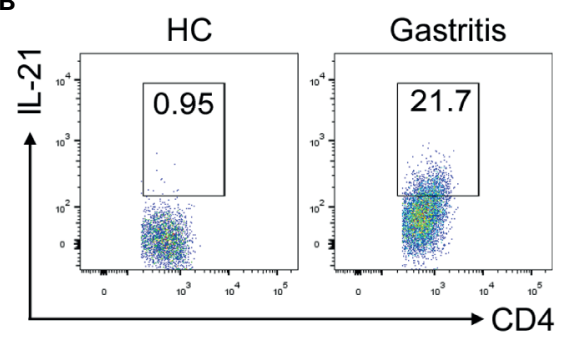

C

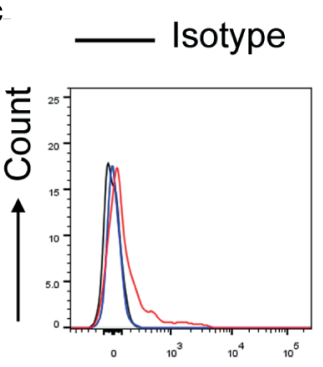

BTLA

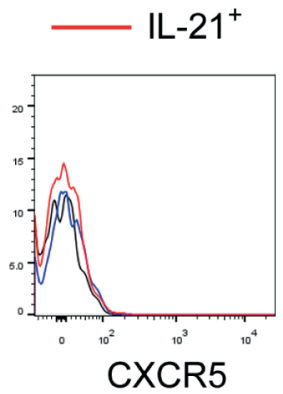

CXCR5

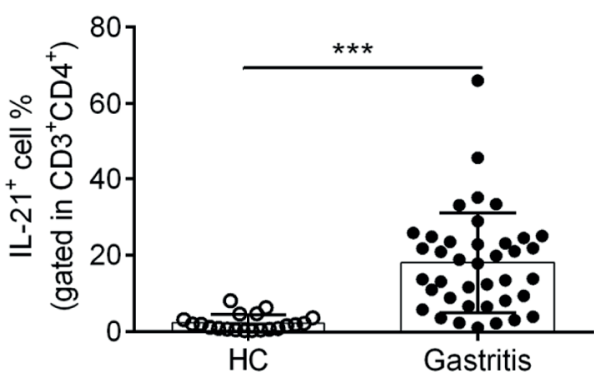

IL-21-
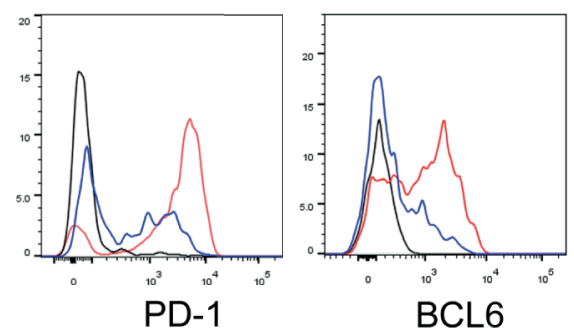

FIGURE 1 | Identification of IL-21 ${ }^{+} \mathrm{TFH}$-like cells in Helicobacter pylori-positive gastritis. The biopsy specimens of gastric mucosa from $\mathrm{H}$. pylori-positive patients ( $\mathrm{n}=$ 39) and healthy controls $(n=20)$ were collected. (A) Immunofluorescence was conducted to determine the co-localization of CD4 (green) with IL-21 (red). The nucleus was stained with DAPI (blue). Scale bar: $100 \mu \mathrm{m}$. (B) The percentage of IL-21 ${ }^{+} \mathrm{CD} 4^{+} \mathrm{T}$ cells in the gastric mucosa was detected by flow cytometry. (C) The expression of BTLA, CXCR5, PD-1, and BCL6 in IL-21+ or IL-21- CD4+ ${ }^{+}$cells was assessed by flow cytometry. Unpaired Student's t-test was performed to determine the difference between two groups. Data represent mean $\pm \mathrm{SD}$ from at least three independent experiments. ${ }^{\star \star \star} P<0.001$.

gastric $\mathrm{CD} 4^{+} \mathrm{T}$ cell stimulated with $\mathrm{CD} 3$-activating $\mathrm{Ab}$, whereas inhibition of STAT3 substantially restrained the BCL6 expression and suppressed the IL-21 concentration in the culture supernatant of gastric $\mathrm{CD} 4^{+} \mathrm{T}$ cells induced by recombinant GITRL protein (Figures 4C, D). These data demonstrated that STAT3 signal played a critical role in GITR-mediated TFH-like cell polarization and IL-21 secretion in $H$. pylori-positive gastritis.

\section{IL-21 ${ }^{+}$TFH-Like Cells Induce B Cell Proliferation in $\boldsymbol{H}$. pylori-Positive Gastritis}

TFH cells support the proliferation and differentiation of germinal center B cells in lymph nodes (7). To fully elucidate the role of IL- $21^{+} \mathrm{TFH}$-like cells in $H$. pylori-positive gastritis, we next explored the regulatory role of IL- $21^{+} \mathrm{TFH}$-like cells in $B$ cell function. We firstly analyzed the percentage of gastric $\mathrm{CD} 19^{+} \mathrm{B}$ cells as well as the correlation between the percentage of IL- $21^{+} \mathrm{CD} 4^{+} \mathrm{T}$ cells and $\mathrm{CD} 19^{+} \mathrm{B}$ cells in $H$. pylori-positive gastritis patients. Data showed that the percentage of IL$21^{+} \mathrm{CD} 4^{+} \mathrm{T}$ cells was positively correlated with the frequency of $\mathrm{B}$ cells in the mucosa of $H$. pylori-positive gastritis patients (Figure 5A). Meanwhile, a positive correlation was also observed between the percentage of $\mathrm{GITR}^{+} \mathrm{CD} 4^{+} \mathrm{T}$ cells and $\mathrm{B}$ cell frequency in the gastric mucosa of gastritis patients (Figure 5B). Furthermore, we utilized the co-culture system to investigate the role of IL- $21^{+} \mathrm{TFH}-$ like cells in gastric $\mathrm{B}$ cell response. Gastric mucosal $\mathrm{CD}^{+} \mathrm{T}$ cells were isolated and pre- 

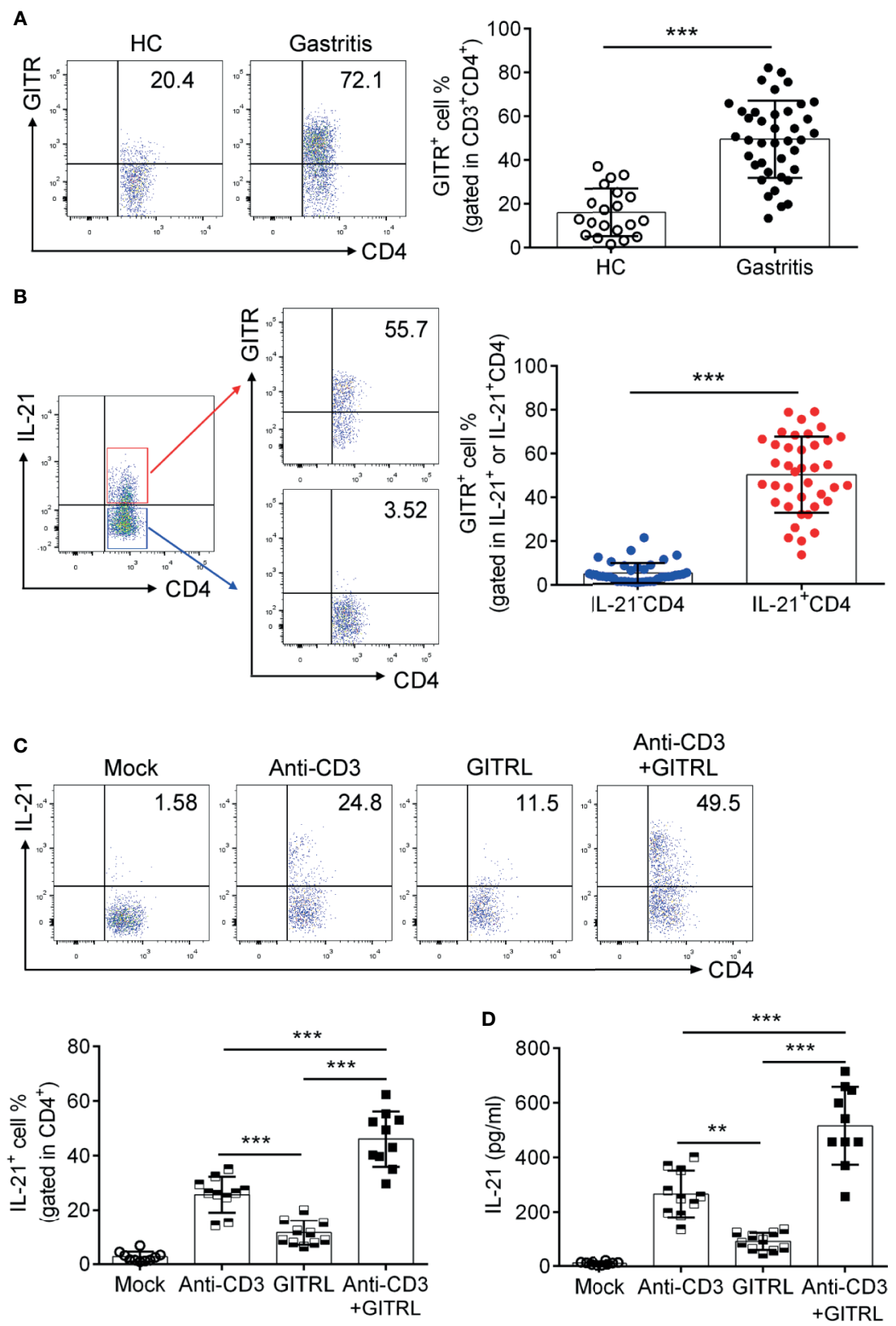

FIGURE 2 | Glucocorticoid-induced tumor necrosis factor receptor (GITR) promoted the polarization of 21+TFH-like cells in Helicobacter pylori-positive gastritis. Biopsy samples of gastric mucosa from H. pylori-positive patients $(n=39)$ and healthy controls $(n=20)$ were collected. The GITR expression in (A) CD4 $4^{+} T$ cells and (B) IL-21 $1^{+}$or IL-21-CD4 $4^{+} T$ cells was determined by flow cytometry. (C) The sorted gastric CD4 ${ }^{+} T$ cells were stimulated with CD3 agonist Ab or recombinant GITRL protein. At 3 days later, IL-21 production by $C D 4^{+} T$ cells was determined by flow cytometry. (D) CD4 ${ }^{+} T$ cells were isolated from the gastric mucosa of $H$. pyloripositive patients and treated with CD3 agonist Ab or recombinant GITRL protein. At 3 days later, the IL-21 concentration in the culture supernatant was determined by ELISA. Unpaired Student's $t$-test was performed to determine the difference between the two groups. One-way ANOVA was used to compare among three or multiple groups. Data are displayed as mean \pm SD from at least three independent experiments. ${ }^{\star \star} P<0.01 ;{ }^{\star \star \star} P<0.001$.

treated with $\mathrm{CD} 3$-activating $\mathrm{Ab}$ and recombinant GITRL protein. The primed $\mathrm{CD} 4^{+} \mathrm{T}$ cells were co-cultured with blood $\mathrm{CD} 19^{+} \mathrm{B}$ cell labeled with carboxyfluorescein succinimidyl ester in the presence of anti-IL-21-neutralizing Ab or control IgG. The results showed that B cells co-cultured with $\mathrm{CD} 4^{+} \mathrm{T}$ cells from $H$. pylori-positive gastritis patients had a higher ratio of proliferation compared to those co-cultured with $\mathrm{CD}^{+} \mathrm{T}$ cells from healthy controls (Figure 5C). Furthermore, the blockage of IL-21 in the coculture system inhibited $\mathrm{B}$ cell proliferation induced by $\mathrm{CD} 4^{+} \mathrm{T}$ cells from $H$. pylori-positive gastritis patients (Figure 5C). These data indicated that the gastric mucosal TFH-like cells promoted $\mathrm{B}$ cell response via IL-21 in $H$. pylori-positive gastritis. 
A

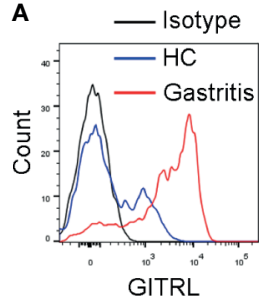

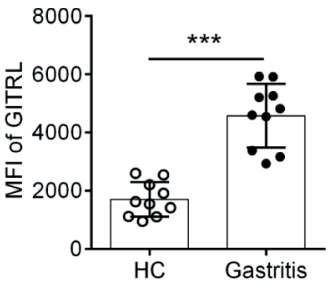

B

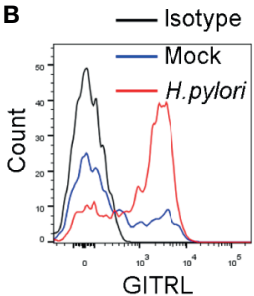

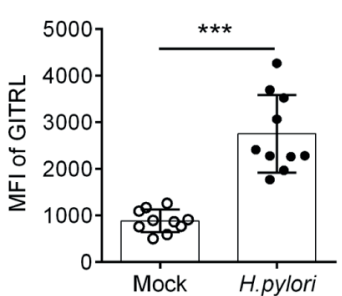

C
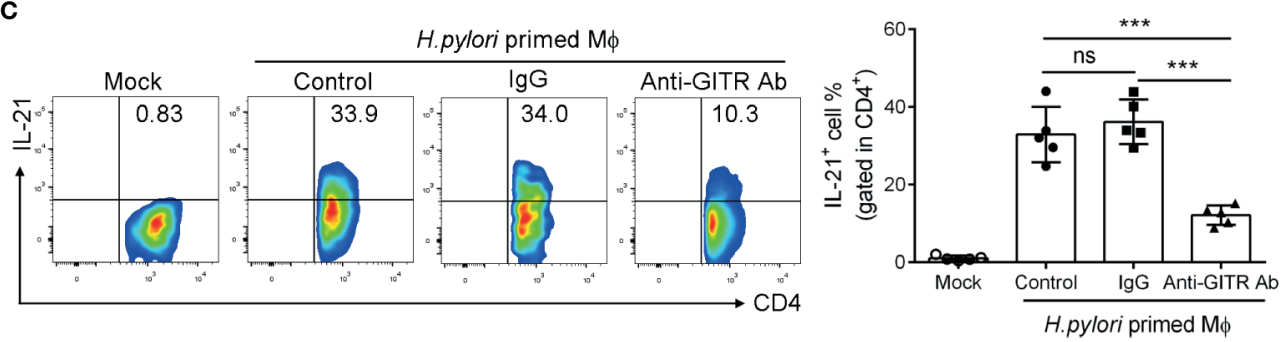

FIGURE 3 | GITRL was upregulated in macrophage and provided ligand signal to TFH-like cells in Helicobacter pylori-positive gastritis. (A) GITRL expression was determined in the mucosal macrophage of $\mathrm{H}$. pylori-positive patients $(n=10)$ and healthy controls $(n=10)$ by flow cytometry. (B) Monocyte-derived macrophages (MDM) were infected with $\mathrm{H}$. pylori (multiplicity of infection, $\mathrm{MOI}=20$ ) for $24 \mathrm{~h}$. GITRL expression was assessed by flow cytometry. (C) MDM was infected with $\mathrm{H}$. pylori $(\mathrm{MOI}=20)$ and co-cultured with gastric $\mathrm{CD} 4^{+} T$ cells in the presence of control IgG or anti-GITR-neutralizing Ab. At 3 days later, IL-21 production by CD4 ${ }^{+} T$ cells was detected. Unpaired Student's $t$-test was performed to determine the difference between the two groups. One-way ANOVA was used to compare among three or multiple groups. Data are shown as mean \pm SD from at least three independent experiments. $\mathrm{ns}, P>0.05 ;{ }^{\star \star \star} P<0.001$.

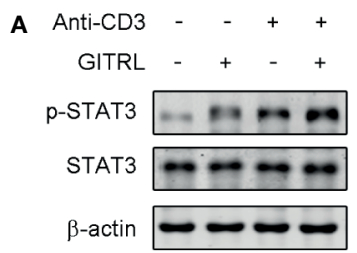

C

Mock

- Control+DMSO

- GITRL+DMSO

- - Control+Stattic

- - GITRL+Stattic

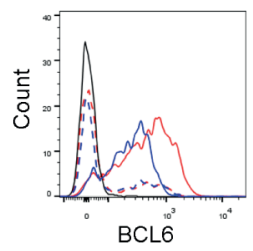

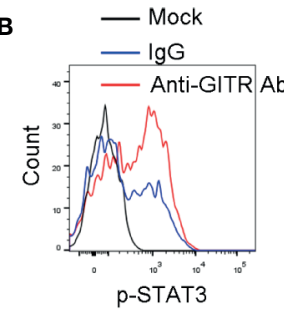

B

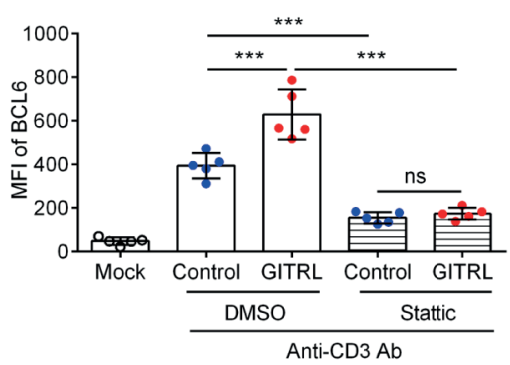

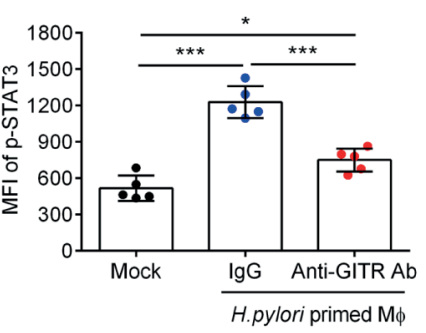

D

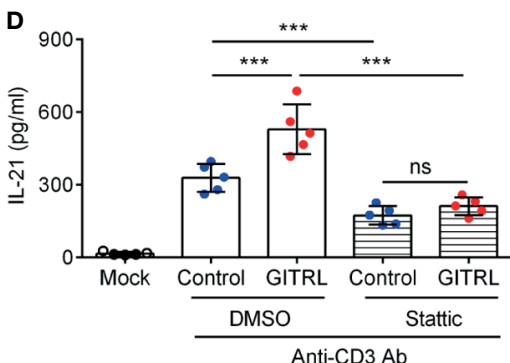

FIGURE 4 | Glucocorticoid-induced tumor necrosis factor receptor (GITR) promoted IL2 $21^{+}$TFH-like cell polarization dependent on the STAT3 signal pathway in Helicobacter pylori infection. (A) Gastric CD4 ${ }^{+} \mathrm{T}$ cells were isolated from the gastric mucosa of $H$. pylori-positive patients and treated with CD3 agonist Ab or recombinant GITRL protein for $12 \mathrm{~h}$. Western blot was performed to detect the expression of phosphorylated STAT3 (Ser727) and total STAT3. (B) Monocytederived macrophages were infected with $\mathrm{H}$. pylori (multiplicity of infection $=20$ ) and co-cultured with gastric CD4 ${ }^{+} \mathrm{T}$ cells with the addition of control lgG or anti-GITRneutralizing Ab. At $12 \mathrm{~h}$ later, the phosphorylated level of STAT3 (Ser727) in CD4 ${ }^{+} \mathrm{T}$ cells was determined by flow cytometry. (C, D) Sorted gastric CD4 ${ }^{+} \mathrm{T}$ cells were pretreated with stattic or dimethyl sulfoxide for $1 \mathrm{~h}$ and stimulated with CD3 agonist Ab or recombinant GITRL protein for 3 days. (C) The BCL6 expression in CD4 ${ }^{+} \mathrm{T}$ cells was detected by flow cytometry. (D) The IL-21 concentration in the culture supernatant was determined by ELISA. One-way ANOVA was used to compare among three or multiple groups. Data represent mean $\pm \mathrm{SD}$ from at least three independent experiments. $\mathrm{ns}, P>0.05$; ${ }^{\star} P<0.05 ;{ }^{\star \star \star} P<0.001$. 

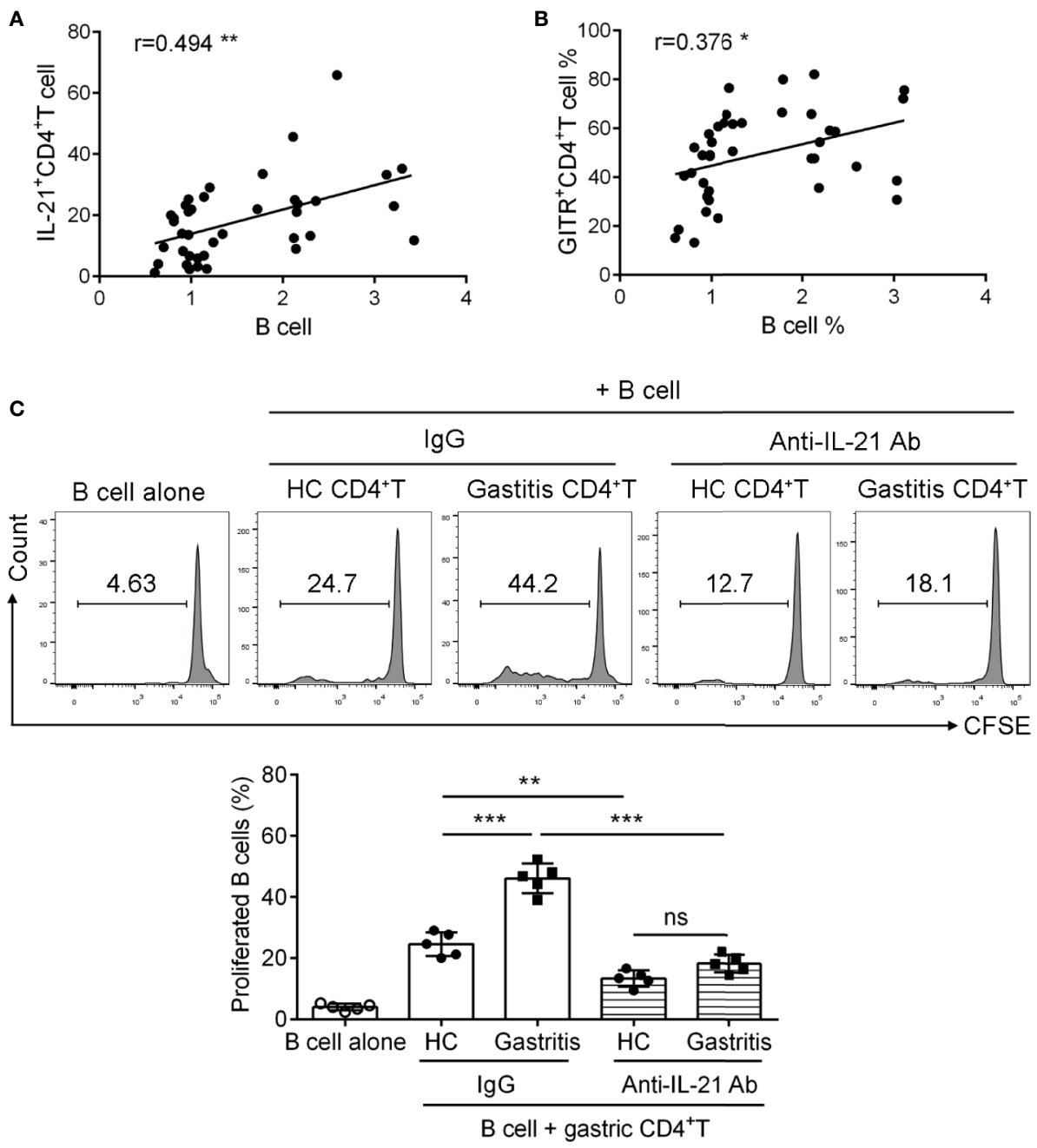

FIGURE 5 | IL-21 TFH-like cells induced B cell proliferation in Helicobacter pylori-positive gastritis. (A, B) The correlations of B cell proportion with (A) IL-21 and (B) glucocorticoid-induced tumor necrosis factor receptor expression in mucosal $C D 4^{+} T$ cells of $H$. pylori-positive gastritis patients were analyzed by Spearman correlation analysis $(n=39)$. (C) The gastric CD4 ${ }^{+} T$ cells were respectively isolated from the gastric mucosa of $H$. pylori-positive patients and healthy controls and treated with CD3 Ab or recombinant GITRL protein for $12 \mathrm{~h}$. Then, the gastric CD4 ${ }^{+} T$ cells were co-cultured with carboxyfluorescein succinimidyl ester-labeled autologous $\mathrm{CD} 19^{+} \mathrm{B}$ cells in the presence of $\mathrm{IgG}$ or anti-IL-21-neutralizing Ab. At 3 days later, the percentage of proliferated B cells was assessed by flow cytometry. One-way ANOVA was used to compare among three or multiple groups. Data are shown as mean \pm SD from at least three independent experiments. ns, $P>0.05$; ${ }^{\star} P<0.05 ;{ }^{* *} P<0.01 ;{ }^{* \star} P<0.001$.

\section{IL-21+TFH-Like Cells Promote the Production of Pro-Inflammatory Cytokines and Chemokines as Well as the Secretion of Matrix Metalloproteinases in Human Gastric Epithelial Cells}

Human gastric mucosa infected by $H$. pylori triggers the release of inflammatory effectors such as cytokines and chemokines (32). To explore the relevance of IL-21-producing TFH-like cells with $H$. pylori-induced mucosal inflammation, we collected the culture supernatant of gastric $\mathrm{CD} 4^{+} \mathrm{T}$ cells stimulated with anti-CD3 agonist $\mathrm{Ab}$ or recombinant GITRL protein to treat human gastric epithelial cell line GES-1 cells in the presence of IL-21-neutralizing $\mathrm{Ab}$. The results showed that the culture supernatant of $\mathrm{CD} 4^{+} \mathrm{T}$ cell from $H$. pylori-positive gastritis patients induced higher levels of pro-inflammatory cytokine IL-6 and IL-1 $\beta \beta$ as well as chemokine macrophage inflammatory protein (MIP-3 $\alpha$ ) and CCL-25 in GES-1 cells compared to the supernatant of $\mathrm{CD}^{+}{ }^{+} \mathrm{T}$ cell from healthy controls (Figures 6A-D). Furthermore, the blockage of IL-21 with neutralizing $\mathrm{Ab}$ reduced the production of cytokines and chemokines in GES-1 (Figures 6A-D). A previous study reported that IL-21 enhanced MMP secretion in human intestinal fibroblasts (14). We demonstrated that the culture supernatant of $\mathrm{CD} 4^{+} \mathrm{T}$ cell from $H$. pylori-positive gastritis patients promoted MMP3 and MMP9 secretion of GES-1 cells (Figure 6E). Simultaneously, IL21 blockage decreased MMP3 and MMP9 secretion (Figure 6E). Taking these data together, it is indicated that IL-21 produced by mucosal TFH-like cells promoted the production of pro- 
A

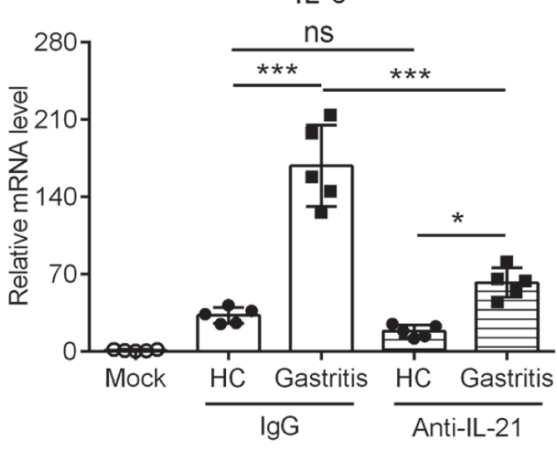

C

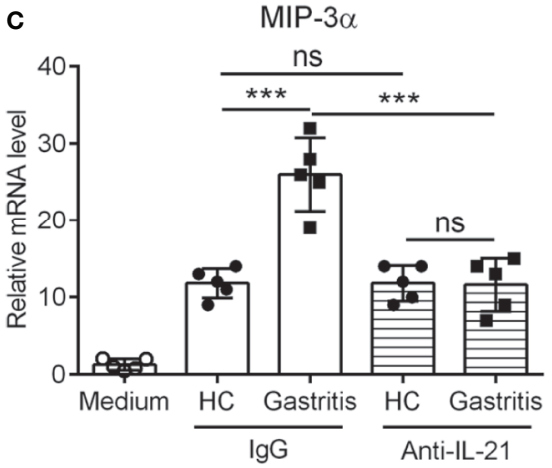

B

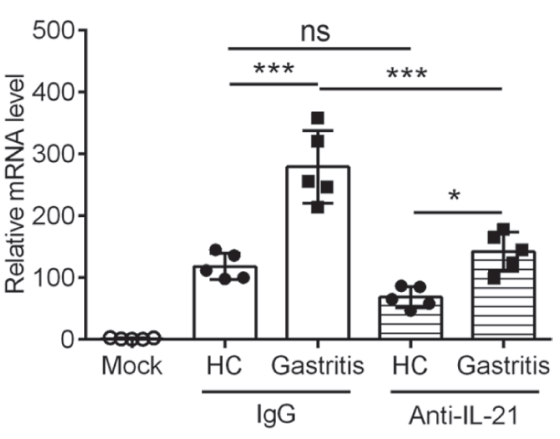

D

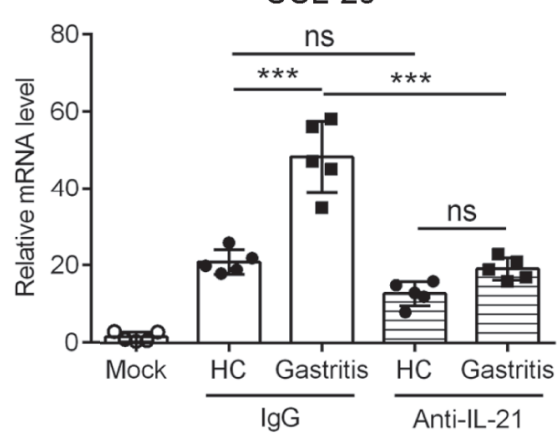

E

$\mathrm{HC} C D 4^{+} \mathrm{T}$ supernatant

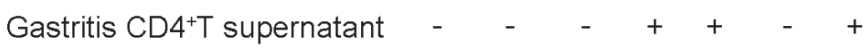

$\lg \mathrm{l}-\mathrm{C}_{-}+\mathrm{C}_{-}+$

Anti-IL-21 Ab

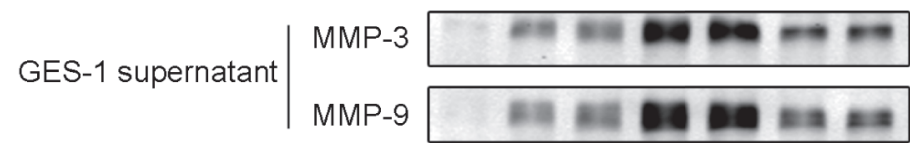

GES-1 total protein $\mid \beta$-actin

FIGURE 6 | IL-21 TFH-like cells induced the expression of pro-inflammatory cytokines and matrix metalloproteinases in human gastric epithelial cells. The gastric $\mathrm{CD} 4^{+} T$ cells were isolated from the gastric mucosa of Helicobacter pylori-positive patients and healthy controls and stimulated with CD3 agonist Ab or recombinant GITRL protein. At 3 days later, the culture supernatant was collected. GES- 1 cells were treated with $20 \%$ culture supernatant of gastric CD4 ${ }^{+} T$ cells with the addition of control IgG or anti-IL-21-neutralizing Ab for $24 \mathrm{~h}$. The mRNA expressions of IL-6 (A), IL-1 $\beta \beta$; (B), MIP-3 $\alpha \alpha$ (C), and CCL-25 (D) were determined by real-time PCR. (E) MMP-3, MMP-9, and $\beta$-actin expression in the culture supernatants or total extracts of GES-1 cells was detected by western blot. One-way ANOVA was used to compare among three or multiple groups. Data are shown as mean $\pm \mathrm{SD}$ from at least three independent experiments. ns, $P>0.05$; ${ }^{\star} P<0.05$; ${ }^{\star \star \star} P<0.001$.

inflammatory cytokines and chemokines and facilitated the secretion of matrix metalloproteinases in gastric epithelial cells during $H$. pylori-positive gastritis.

\section{DISCUSSION}

In the present study, we explored the regulatory role of the GITR/ GITRL axis in facilitating mucosal TFH-like cell activation and IL21 production in $H$. pylori-positive gastritis patients. Our findings revealed the critical T cell subset contributing to $H$. pylori-mediated gastritis, and we investigated the potentially modulatory mechanisms, which may provide intervening strategies for the clinical management of $H$. pylori-induced gastritis.

GITR is a TNFRSF member widely studied in multiple $\mathrm{T}$ cell subsets, such as Treg, Th9, and Th17 $(27,33)$. Studies indicate that GITR plays a key role in TFH cell differentiation. During chronic lymphocytic choriomeningitis virus (LCMV) infection or collageninduced arthritis (CIA), GITR expression is upregulated on TFH cells rather than non-TFH cells $(34,35)$. Meanwhile, the 
administration of GITR-Fc protein significantly alleviated CIA symptoms and joint damage via suppressing TFH cell generation and the production of autoantibodies (34). An impaired TFH generation was observed in GITR knockout mice after chronic LCMV infection (35). Specifically, GITR promotes TFH cell proliferation, thereby favoring antibody production to fight against chronic LCMV infection (35). Taking these results together, the GITR signal positively modulates TFH cell generation. It is reported that TFH cells are induced in the gut mucosa of mice infected with $H$. pylori (36). However, the role of GITR in $H$. pylori-infected gastritis remains unclear. In this study, we found that GITR promoted the polarization of mucosal TFHlike $\mathrm{CD} 4^{+} \mathrm{T}$ cells during $H$. pylori infection. GITRL was upregulated in $H$. pylori-infected macrophage and provided a ligand signal to GITR-expressed $\mathrm{CD}^{+} \mathrm{T}$ cells, which induced TFH-like cell polarization. The STAT3 signal pathway is essential for classical TFH cell differentiation (31), and we demonstrated here that GITR promoted TFH-like cell polarization via STAT3 signal in $H$. pyloripositive gastritis.

IL-21 is a characteristic cytokine mainly secreted by TFH cells (6). It is reported to be highly produced in $H$. pylori-infected gastric mucosa and promote the synthesis of gelatinases (18). IL-21 could maintain pro-inflammatory $\mathrm{T}$ cell response to drive $H$. pylori infection-induced chronic gastritis (19). Here we identified a subset of tissue-resident CXCR5 BTLA-PD-1 ${ }^{\text {hi }}$ TFH-like cells with IL-21 production in the mucosal tissue of $H$. pylori-positive gastritis patients.

In secondary lymphoid tissues, TFH cells exert a crucial function in the formation of the GC and the development of T cell-dependent B cell responses (6). Many clinical studies have indicated that $H$. pylori infection is a key factor of gastric mucosa-associated lymphoid tissue (MALT) lymphoma (37-39). Gastric MALT lymphoma is a Bcell lymphoma that is induced in mucosal barriers. The infection of H. pylori is significantly related to lymphoid follicle formation, regarded as the first step in MALT lymphomagenesis of lymphoid expansion (40). Murine model data reveals that Helicobacter spp. infection results in pathophysiological alternations that take place at the early phase of MALT lymphomagenesis (41). Dysregulated TFH cells could induce GC B cell outgrowth and lymphomagenesis (42). In this study, we found that gastric TFH-like cell significantly induced B cell proliferation via IL-21, which may explain the early lymphomagenesis induced by $H$. pylori infection.

Gut epithelial cells take part in immune response through responding to bacteria, presenting antigens, and secreting cytokines to regulate the activity of mucosal immunity. More importantly, IL$21 \mathrm{R}$ is constitutively expressed in intestinal epithelial cells, and its expression is further elevated in the inflamed tissue of UC and CD patients compared with normal controls (16), indicating the probable direct target of IL-21 to intestinal epithelial cells. In vitro experiments also show that IL-21 enhances the secretion of MIP-3 $\alpha$ by epithelial cell lines (15). MIP-3 $\alpha$ ocan bind chemokine receptor CCR6 which is expressed in immune cells, suggesting that MIP- $3 \alpha$ might foster the migration and accumulation of immune cells in the gut lamina propria during chronic inflammation.

The physiologic reactions to inflammation-associated damage led to the injuries of the original mucosal structure. The primary players during this process are the myofibroblasts and fibroblasts located in the lamina propria, which produce large amounts of MMPs in inflammatory conditions (43). MMPs are a class of neutral endopeptidases that cleave various components of the extracellular matrix. It has been recently reported that IL-21R is expressed by gut fibroblasts, and the stimulation of IL-21 results in the increased release of MMP-1, MMP-2, MMP-3, and MMP-9 (14). The neutralization of IL-21 significantly reduces MMP secretion when fibroblasts are treated with the culture supernatants of lamina propria mononuclear cells from $\mathrm{CD}$ patients, demonstrating the role of IL-21 in MMP-mediated tissue damage.

In conclusion, our data showed that GITR was upregulated on gastric TFH-like cell after $H$. pylori infection. The GITR/GITRL axis enhanced gastric IL-21 production by TFH-like cells. IL-21, produced by mucosal TFH-like cells, induced the B cell proliferation and inflammatory response of gastric epithelial cells. These findings shed light on the function of IL-21producing TFH-like cells regulated by the GITR/GITRL axis in H. pylori-positive gastritis and held the implications for the therapeutic purpose of $H$. pylori-induced gastritis.

\section{MATERIALS AND METHODS}

\section{Ethics Statement}

This study was approved by the Ethics Committee of Guangzhou Women and Children's Medical Center, Guangzhou Medical University (approval number 2017021709). The biopsy specimens of $H$. pylori-positive patients and healthy controls were collected from Guangzhou Women and Children's Medical Center (Guangzhou, China). Informed written consents were obtained from all participants prior to the commencement of the study.

\section{Subjects}

Twenty healthy controls and 39 gastritis patients who appeared with chronic symptoms of peptic disease, including dyspepsia and recurrent abdominal discomfort or pain, were enrolled in this study. The exclusive criteria included a history of acute onset of symptoms, acute or chronic vomiting, and the use of antibiotic, antacid, $\mathrm{H} 2$ blockers, proton pump inhibitors, bismuth-containing compounds, or non-steroidal anti-inflammatory drugs within the preceding 4 weeks. Biopsy specimens were obtained from the patients with indications for gastroscopy examination. The samples were stained with Giemsa dye to observe $H$. pylori under a light microscopy. All 39 patients were diagnosed as cases of $H$. pylori-positive gastritis with pathological changes of the mucosa, whereas 20 healthy controls are $H$. pylori-negative and with normal mucosa (see Table 1).

\section{Preparation of Mucosal Mononuclear Cells}

Mucosal mononuclear cells were isolated from the gastric mucosa biopsy of the patients as previously described (4). Briefly, biopsy specimens were digested with shaking at $37^{\circ} \mathrm{C}$ for $45 \mathrm{~min}$. The digestion solution is composed of RPMI 1640 medium (Gibco) containing 10\% collagenase D $(100 \mu \mathrm{g} / \mathrm{ml}$; Sigma-Aldrich, St. Louis, MO, USA) and 1\% DNase I (10 $\mu \mathrm{g} /$ ml; Thermo Fisher Scientific, Waltham, MA, USA). After 
complete digestion, the cells were filtered via a $70-\mu \mathrm{m}$ cell filter and collected by centrifuging at 1,500 rpm. Then, the cells were washed and suspended with RPMI 1640 for the following experiments, including cell sorting, co-culture assay, flow cytometry, and immunofluorescence staining (see below).

\section{Cell Sorting}

$\mathrm{CD} 4^{+} \mathrm{T}$ cells were isolated from mucosal mononuclear cells by positive selection with magnetic cell sorting system of $\mathrm{BD}$ Biosciences. The purity of sorted $\mathrm{CD} 4^{+} \mathrm{T}$ cells was determined as $>95 \%$ by flow cytometry, gated on $\mathrm{CD} 3^{+} \mathrm{CD} 4^{+} \mathrm{T}$ cells.

$\mathrm{CD} 14^{+}$monocytes were sorted from human peripheral blood mononuclear cells by positive selection with human CD14 magnetic particles (BD). MDM was generated from monocytes as previously described (44). In brief, $\mathrm{CD} 14^{+}$monocytes were differentiated into MDM in the presence of $10 \mathrm{ng} / \mu \mathrm{l}$ macrophage colony-stimulating factor for 5 days.

\section{Co-Culture Assay}

MDM were pre-incubated with $H$. pylori (multiplicity of infection, MOI $=20$ ) for $24 \mathrm{~h}$. After the incubation, the M $\phi$ were irradiated, fully washed, and co-cultured with gastric $\mathrm{CD} 4^{+} \mathrm{T}$ cells at a ratio of 1:5 in a 96-well flat-bottomed plate $\left(2 \times 10^{4} \mathrm{M} \phi\right.$ and $1 \times 10^{5} \mathrm{CD}^{+} \mathrm{T}$ cells per well). The percentage of IL-21-producing $\mathrm{CD} 4^{+} \mathrm{T}$ cells was calculated by gating on live $\mathrm{CD} 4^{+} \mathrm{T}$ cells.

To evaluate the effect of GITR on the IL-21 production of $\mathrm{CD}^{+} \mathrm{T}$ cells, recombinant human GITR ligand $(10 \mu \mathrm{g} / \mathrm{ml}$, BioLegend, Product \#559206), blocking antibody (Ab) of GITR $(10 \mu \mathrm{g} / \mathrm{ml}$, Clone 621, BioLegend), and agonist Ab of CD3 (10 $\mu \mathrm{g} / \mathrm{ml}$, Clone $\mathrm{UCHT} 1, \mathrm{BD})$ were added to the co-culture system. At 3 days later, the secretion of IL- 21 by $\mathrm{CD} 4^{+} \mathrm{T}$ cells was determined by flow cytometry.

\section{Flow Cytometry Analysis}

The procedure of cell staining and flow cytometry was previously described (5). For intracellular staining of IL-21, gastric $\mathrm{CD} 4^{+} \mathrm{T}$ cells were restimulated with $1 \mu \mathrm{g} / \mathrm{ml}$ anti-CD3 Ab (Clone UCHT1, BD), $1 \mu \mathrm{g} / \mathrm{ml}$ anti-CD28 Ab (Clone CD28.2, BD), and $3 \mu \mathrm{g} / \mathrm{ml}$ brefeldinA (eBioscience, CA, USA) for $12 \mathrm{~h}$. The intracellular fixation/permeabilization buffer set (eBioscience, CA, USA) was used in IL-21 staining. Flow cytometric detection was performed with FACS Canto II (BD, NJ, USA). Data was analyzed by the FlowJo software (Tree Star). The antihuman antibodies used in this study were purchased from Biolegend, BD Biosciences, or Miltenyi Biotec, namely: CD3 (Clone UCHT1, BioLegend), CD4 (Clone OKT4, BioLegend), GITR (Clone 108-17, BioLegend), GITRL (Clone REA841, Miltenyi), IL-21 (Clone 3A3-N2.1, BD), BCL6 (Clone 7D1, BioLegend), STAT3 Phospho (Ser727) (Clone A16089B, BioLegend), BTLA (Clone MIH26, BioLegend), CXCR5 (Clone J252D4, BioLegend), and PD-1 (Clone EH12.2H7, BioLegend).

\section{Immunofluorescence Staining and Confocal Microscopy}

Paraffin-embedded samples were cut into $5-\mu \mathrm{m}$ slices, and immunohistochemistry was conducted as previously described (4).
In brief, the mucosa was fixed with paraformaldehyde, followed by antigen retrieval with the EDTA antigen retrieval solution (Servicebio). The processed samples were blocked with 5\% bovine serum albumin (BSA) and subsequently incubated with CD4 (Clone RPA-T4, BioLegend) and IL-21 (Abbiotec, Product \#253397) Abs, followed by staining of secondary Abs Alexa Fluor $^{\circledR} 488$ (Thermo, Product \#A-11034) and Alexa Fluor ${ }^{\circledR}$ 594 (Thermo, Product \#A-11005) as well as DAPI (Thermo, Product \#A-11034) before the detection. Fluorescence images were captured under a ZEISS IMAGER A1 fluorescence microscope (CARL ZEISS).

\section{Western Blot}

The cells were collected, washed three times with cold phosphate-buffered saline (PBS, pH 7.4, Invitrogen), and lysed by RIPA lysis buffer (Sangon Biotech, C500005) containing 1\% (v/v) protease inhibitor cocktail (Merck, P8340), $1 \mathrm{mM}$ phenylmethylsulfonyl fluoride (Merck, 52332), and 1 mM DTT (Merck, DTT-RO). Equivalent amounts $(20 \mu \mathrm{g})$ of cell lysates were separated by SDS-PAGE and then transferred to polyvinylidene difluoride membrane. The membranes were blocked in PBS-Tween20 ( $\mathrm{pH} 7.4,0.5 \%$ Tween20) containing $5 \%$ BSA for $1 \mathrm{~h}$ at room temperature (RT) and then incubated overnight with primary antibodies at $4^{\circ} \mathrm{C}$. On the next day, the membranes were incubated with appropriate horseradish peroxidase-conjugated secondary antibodies at RT for $1 \mathrm{~h}$, followed by visualization with an ECL kit (KeyGEN, Nanjing, China) based on the recommendations of the manufacturer.

\section{Real-Time PCR}

Gastric mucosa was collected and homogenized by bead-milling as previously described (4). The cells were lysed, and total RNA was extracted with TRIzol reagent (Invitrogen) (refer to the instructions of the manufacturer). The synthesis of first-strand cDNA was performed by Synthesis Kit (Ref). The expression level of the indicated genes (IL-6, IL-1 $\beta$, MIP-3 $\alpha$, CCL-25, and $\beta$-actin) was examined by real-time PCR amplification using SYBR Green Master Mix kit (Invitrogen) and detected with the Bio-Rad CFX96 real-time detection system. The mRNA expression of the target genes relative to $\beta$-actin was calculated according to the following formula: relative mRNA expression $=2^{\text {CT value (actin-target gene) }}$.

\section{ELISA}

The concentration of IL-21was detected by Human IL-21 ELISA kit (MultiSciences, Product \#70-EK121HS) according to the manufacturer's instructions. For IL-21 release of $\mathrm{CD}^{+} \mathrm{T}$ cells, gastric $\mathrm{CD} 4^{+} \mathrm{T}$ cells were isolated and restimulated with $1 \mu \mathrm{g} / \mathrm{ml}$ $\mathrm{CD} 3 \mathrm{Ab}$ and $10 \mu \mathrm{g} / \mathrm{ml}$ recombinant GITRL protein for 3 days, followed by the collection of the culture supernatant for ELISA assay.

\section{Statistical Analysis}

Statistical analysis was performed with GraphPad Prism 5.0 (GraphPad Software, San Diego, CA). Significance was analyzed by chi-square test, Spearman correlation analysis, 
one-way analysis of variance, or unpaired Student's $t$-tests. Data are shown as mean \pm SD unless otherwise indicated. $P$-value less than 0.05 is considered significant.

\section{DATA AVAILABILITY STATEMENT}

The original contributions presented in the study are included in the article/supplementary material. Further inquiries can be directed to the corresponding author.

\section{ETHICS STATEMENT}

This study was approved by the Ethics Committee of Guangzhou Women and Children's Medical Center, Guangzhou Medical University (approval number 2017021709). The patients/ participants provided their written informed consent to participate in this study.

\section{REFERENCES}

1. Algood HMS. T Cell Cytokines Impact Epithelial Cell Responses During Helicobacter Pylori Infection. J Immunol (2020) 204(6):1421-8. doi: 10.4049/ jimmunol.1901307

2. Jafarzadeh A, Larussa T, Nemati M, Jalapour S. T Cell Subsets Play an Important Role in the Determination of the Clinical Outcome of Helicobacter Pylori Infection. Microb Pathog (2018) 116:227-36. doi: 10.1016/ j.micpath.2018.01.040

3. Genta RM. Helicobacter Pylori, Inflammation, Mucosal Damage, and Apoptosis: Pathogenesis and Definition of Gastric Atrophy. Gastroenterology (1997) 113(6 Suppl):S51-5. doi: 10.1016/s0016-5085(97) 80012-1

4. Ming S, Zhang M, Liang Z, Li C, He J, Chen P, et al. OX40L/OX40 Signal Promotes IL-9 Production by Mucosal MAIT Cells During Helicobacter Pylori Infection. Front Immunol (2021) 12:626017. doi: 10.3389/ fimmu.2021.626017

5. Chen P, Ming S, Lao J, Li C, Wang H, Xiong L, et al. CD103 Promotes the ProInflammatory Response of Gastric Resident CD4(+) T Cell in Helicobacter Pylori-Positive Gastritis. Front Cell Infect Microbiol (2020) 10:436. doi: $10.3389 /$ fcimb. 2020.00436

6. Jogdand GM, Mohanty S, Devadas S. Regulators of Tfh Cell Differentiation. Front Immunol (2016) 7:520. doi: 10.3389/fimmu.2016.00520

7. Crotty S. Follicular Helper CD4 T Cells (TFH). Annu Rev Immunol (2011) 29:621-63. doi: 10.1146/annurev-immunol-031210-101400

8. Long D, Chen Y, Wu H, Zhao M, Lu Q. Clinical Significance and Immunobiology of IL-21 in Autoimmunity. J Autoimmun (2019) 99:1-14. doi: 10.1016/j.jaut.2019.01.013

9. Ozaki K, Spolski R, Feng CG, Qi CF, Cheng J, Sher A, et al. A Critical Role for IL-21 in Regulating Immunoglobulin Production. Science (2002) 298 (5598):1630-4. doi: 10.1126/science.1077002

10. Ozaki K, Spolski R, Ettinger R, Kim HP, Wang G, Qi CF, et al. Regulation of B Cell Differentiation and Plasma Cell Generation by IL-21, A Novel Inducer of Blimp-1 and Bcl-6. J Immunol (2004) 173(9):5361-71. doi: 10.4049/ jimmunol.173.9.5361

11. Nurieva R, Yang XO, Martinez G, Zhang Y, Panopoulos AD, Ma L, et al. Essential Autocrine Regulation by IL-21 in the Generation of Inflammatory T Cells. Nature (2007) 448(7152):480-3. doi: 10.1038/nature05969

12. Guan LJ, Wang X, Meng S, Shi LF, Jiang WJ, Xiao L, et al. Increased IL-21/IL21R Expression and Its Proinflammatory Effects in Autoimmune Thyroid Disease. Cytokine (2015) 72(2):160-5. doi: 10.1016/j.cyto.2014.11.005

\section{AUTHOR CONTRIBUTIONS}

SM and YW initiated and designed the research. SM, YW, and SG wrote the manuscript with the help of other co-authors. SM, $\mathrm{HY}$, and XL performed the experiments and analyzed and/or interpreted the results. YW, GZ, and SG were in charge of patient care and contributed to the discussion of the results. All authors contributed to the article and approved the submitted version.

\section{FUNDING}

This work was supported by grants from the National Natural Science Foundation of China (81770552, 81801571 and 82102249), the China Postdoctoral Science Foundation (2020T130131), the National Key Research and Development Plan (2019YFC0840602), the Guangdong Scientific and Technological Foundation (2020B1111170014 and 2019A1515110055), and the Shenzhen Scientific and Technological Foundation (KCXFZ20200 2011007083 and JCYJ20180228162321234).

13. Jungel A, Distler JH, Kurowska-Stolarska M, Seemayer CA, Seibl R, Forster A, et al. Expression of Interleukin-21 Receptor, But Not Interleukin-21, in Synovial Fibroblasts and Synovial Macrophages of Patients With Rheumatoid Arthritis. Arthritis Rheum (2004) 50(5):1468-76. doi: 10.1002/ art. 20218

14. Monteleone G, Caruso R, Fina D, Peluso I, Gioia V, Stolfi C, et al. Control of Matrix Metalloproteinase Production in Human Intestinal Fibroblasts by Interleukin 21. Gut (2006) 55(12):1774-80. doi: 10.1136/gut.2006.093187

15. Caruso R, Fina D, Peluso I, Stolfi C, Fantini MC, Gioia V, et al. A Functional Role for Interleukin-21 in Promoting the Synthesis of the T-Cell Chemoattractant, MIP-3alpha, by Gut Epithelial Cells. Gastroenterology (2007) 132(1):166-75. doi: 10.1053/j.gastro.2006.09.053

16. Monteleone G, Monteleone I, Fina D, Vavassori P, Del Vecchio Blanco G, Caruso R, et al. Interleukin-21 Enhances T-Helper Cell Type I Signaling and Interferon-Gamma Production in Crohn's Disease. Gastroenterology (2005) 128(3):687-94. doi: 10.1053/j.gastro.2004.12.042

17. Fantini MC, Rizzo A, Fina D, Caruso R, Becker C, Neurath MF, et al. IL-21 Regulates Experimental Colitis by Modulating the Balance Between Treg and Th17 Cells. Eur J Immunol (2007) 37(11):3155-63. doi: 10.1002/eji.200737766

18. Caruso R, Fina D, Peluso I, Fantini MC, Tosti C, Del Vecchio Blanco G, et al. IL-21 Is Highly Produced in Helicobacter Pylori-Infected Gastric Mucosa and Promotes Gelatinases Synthesis. J Immunol (2007) 178(9):5957-65. doi: 10.4049/jimmunol.178.9.5957

19. Carbo A, Olivares-Villagomez D, Hontecillas R, Bassaganya-Riera J, Chaturvedi R, Piazuelo MB, et al. Systems Modeling of the Role of Interleukin-21 in the Maintenance of Effector CD4+ T Cell Responses During Chronic Helicobacter Pylori Infection. mBio (2014) 5(4):e01243-14. doi: 10.1128/mBio.01243-14

20. Fazilleau N, McHeyzer-Williams LJ, Rosen H, McHeyzer-Williams MG. The Function of Follicular Helper T Cells Is Regulated by the Strength of T Cell Antigen Receptor Binding. Nat Immunol (2009) 10(4):375-84. doi: 10.1038/ ni. 1704

21. Choi YS, Kageyama R, Eto D, Escobar TC, Johnston RJ, Monticelli L, et al. ICOS Receptor Instructs T Follicular Helper Cell Versus Effector Cell Differentiation via Induction of the Transcriptional Repressor Bcl6. Immunity (2011) 34(6):932-46. doi: 10.1016/j.immuni.2011.03.023

22. McDonald PW, Read KA, Baker CE, Anderson AE, Powell MD, BallesterosTato A, et al. IL-7 Signalling Represses Bcl-6 and the TFH Gene Program. Nat Commun (2016) 7:10285. doi: 10.1038/ncomms10285

23. Schmitt N, Morita R, Bourdery L, Bentebibel SE, Zurawski SM, Banchereau J, et al. Human Dendritic Cells Induce the Differentiation of Interleukin-21 
Producing T Follicular Helper-Like Cells Through Interleukin-12. Immunity (2009) 31(1):158-69. doi: 10.1016/j.immuni.2009.04.016

24. Nocentini G, Riccardi C. GITR: A Modulator of Immune Response and Inflammation. Adv Exp Med Biol (2009) 647:156-73. doi: 10.1007/978-0-38789520-8_11

25. Mahne AE, Mauze S, Joyce-Shaikh B, Xia J, Bowman EP, Beebe AM, et al. Dual Roles for Regulatory T-Cell Depletion and Costimulatory Signaling in Agonistic GITR Targeting for Tumor Immunotherapy. Cancer Res (2017) 77 (5):1108-18. doi: 10.1158/0008-5472.CAN-16-0797

26. Santucci L, Agostini M, Bruscoli S, Mencarelli A, Ronchetti S, Ayroldi E, et al. GITR Modulates Innate and Adaptive Mucosal Immunity During the Development of Experimental Colitis in Mice. Gut (2007) 56(1):52-60. doi: 10.1136/gut.2006.091181

27. Liao G, Detre C, Berger SB, Engel P, de Waal Malefyt R, Herzog RW, et al. Glucocorticoid-Induced Tumor Necrosis Factor Receptor Family-Related Protein Regulates CD4(+)T Cell-Mediated Colitis in Mice. Gastroenterology (2012) 142(3):582-591 e8. doi: 10.1053/j.gastro.2011.11.031

28. Uraushihara $\mathrm{K}$, Kanai $\mathrm{T}$, Ko $\mathrm{K}$, Totsuka $\mathrm{T}$, Makita S, Iiyama $\mathrm{R}$, et al. Regulation of Murine Inflammatory Bowel Disease by CD25+ and CD25CD4+ Glucocorticoid-Induced TNF Receptor Family-Related Gene+ Regulatory T Cells. J Immunol (2003) 171(2):708-16. doi: 10.4049/ jimmunol.171.2.708

29. Sakurai T, Okuyama Y, Kobayashi S, Phung HT, Asao A, Kawabe T, et al. GITR Controls Intestinal Inflammation by Suppressing IL-15-Dependent NK Cell Activity. FASEB J (2020) 34(11):14820-31. doi: 10.1096/ff.202001675R

30. Koh CH, Kim IK, Shin KS, Jeon I, Song B, Lee JM, et al. GITR Agonism Triggers Antitumor Immune Responses Through IL21-Expressing Follicular Helper T Cells. Cancer Immunol Res (2020) 8(5):698-709. doi: 10.1158/23266066.CIR-19-0748

31. Schmitt N, Liu Y, Bentebibel SE, Munagala I, Bourdery L, Venuprasad K, et al. The Cytokine TGF-Beta Co-Opts Signaling via STAT3-STAT4 to Promote the Differentiation of Human TFH Cells. Nat Immunol (2014) 15(9):856-65. doi: 10.1038/ni.2947

32. Tsai HF, Hsu PN. Interplay Between Helicobacter Pylori and Immune Cells in Immune Pathogenesis of Gastric Inflammation and Mucosal Pathology. Cell Mol Immunol (2010) 7(4):255-9. doi: 10.1038/cmi.2010.2

33. Xiao X, Shi X, Fan Y, Zhang X, Wu M, Lan P, et al. GITR Subverts Foxp3(+) Tregs to Boost Th9 Immunity Through Regulation of Histone Acetylation. Nat Commun (2015) 6:8266. doi: 10.1038/ncomms9266

34. Ma J, Feng D, Wei Y, Tian J, Tang X, Rui K, et al. Blockade of GlucocorticoidInduced Tumor Necrosis Factor-Receptor-Related Protein Signaling Ameliorates Murine Collagen-Induced Arthritis by Modulating Follicular Helper T Cells. Am J Pathol (2016) 186(6):1559-67. doi: 10.1016/ j.ajpath.2016.02.010

35. Clouthier DL, Zhou AC, Wortzman ME, Luft O, Levy GA, Watts TH. GITR Intrinsically Sustains Early Type 1 and Late Follicular Helper CD4 T Cell Accumulation to Control a Chronic Viral Infection. PloS Pathog (2015) 11(1): e1004517. doi: 10.1371/journal.ppat.1004517
36. Leber A, Abedi V, Hontecillas R, Viladomiu M, Hoops S, Ciupe S, et al. Bistability Analyses of CD4+ T Follicular Helper and Regulatory Cells During Helicobacter Pylori Infection. J Theor Biol (2016) 398:74-84. doi: 10.1016/ j.jtbi.2016.02.036

37. Wotherspoon AC, Ortiz-Hidalgo C, Falzon MR, Isaacson PG. Helicobacter Pylori-Associated Gastritis and Primary B-Cell Gastric Lymphoma. Lancet (1991) 338(8776):1175-6. doi: 10.1016/0140-6736(91)92035-z

38. Crowe SE. Helicobacter Pylori Infection. N Engl J Med (2019) 380(12):115865. doi: 10.1056/NEJMcp 1710945

39. Nakamura S, Aoyagi K, Furuse M, Suekane H, Matsumoto T, Yao T, et al. BCell Monoclonality Precedes the Development of Gastric MALT Lymphoma in Helicobacter Pylori-Associated Chronic Gastritis. Am J Pathol (1998) 152 (5):1271-9.

40. Siddiqui ST, Naz E, Danish F, Mirza T, Aziz S, Ali A. Frequency of Helicobacter Pylori in Biopsy Proven Gastritis and Its Association With Lymphoid Follicle Formation. J Pak Med Assoc (2011) 61(2):138-41.

41. Craig VJ, Cogliatti SB, Arnold I, Gerke C, Balandat JE, Wundisch T, et al. BCell Receptor Signaling and CD40 Ligand-Independent T Cell Help Cooperate in Helicobacter-Induced MALT Lymphomagenesis. Leukemia (2010) 24(6):1186-96. doi: 10.1038/leu.2010.76

42. Mintz MA, Cyster JG. T Follicular Helper Cells in Germinal Center B Cell Selection and Lymphomagenesis. Immunol Rev (2020) 296(1):48-61. doi: 10.1111/imr.12860

43. Bai X, Bai G, Tang L, Liu L, Li Y, Jiang W. Changes in MMP-2, MMP-9, Inflammation, Blood Coagulation and Intestinal Mucosal Permeability in Patients With Active Ulcerative Colitis. Exp Ther Med (2020) 20(1):269-74. doi: 10.3892/etm.2020.8710

44. Zhang S, Li X, Zhu L, Ming S, Wang H, Xie J, et al. CD163(+) Macrophages Suppress T Cell Response by Producing TGF-Beta in Pediatric Colorectal Polyps. Int Immunopharmacol (2021) 96:107644. doi: 10.1016/j. intimp.2021.107644

Conflict of Interest: The authors declare that the research was conducted in the absence of any commercial or financial relationships that could be construed as a potential conflict of interest.

Publisher's Note: All claims expressed in this article are solely those of the authors and do not necessarily represent those of their affiliated organizations, or those of the publisher, the editors and the reviewers. Any product that may be evaluated in this article, or claim that may be made by its manufacturer, is not guaranteed or endorsed by the publisher.

Copyright $\odot 2021$ Ming, Yin, Li, Gong, Zhang and Wu. This is an open-access article distributed under the terms of the Creative Commons Attribution License (CC BY). The use, distribution or reproduction in other forums is permitted, provided the original author(s) and the copyright owner(s) are credited and that the original publication in this journal is cited, in accordance with accepted academic practice. No use, distribution or reproduction is permitted which does not comply with these terms. 